www.jmscr.igmpublication.org

Impact Factor (SJIF): 6.379

Index Copernicus Value: 71.58

ISSN (e)-2347-176x ISSN (p) 2455-0450

crossref DOI: _https://dx.doi.org/10.18535/jmscr/v6i3.172

Journal Of Medical Science And Clinical Research

\title{
Adverse Drug Reactions (ADRs) and preventability, in elderly DR TB patients admitted at Tuberculosis Hospital in Mumbai, India
}

\author{
Authors \\ Dr Rajendra Nanavare ${ }^{1}$, Dr Daksha Shah $^{2}$, Dr Jagdish Keni ${ }^{3}$, Dr Nilima Kshirsagar \\ ${ }^{1}$ International Union against Tubercular and Lung Diseases and Ex. Medical Superintendent, GTB hospital, \\ Sewri, Mumbai \\ ${ }^{2}$ Deputy Executive Health Officer, Public Health Department, MCGM, Mumbai \\ ${ }^{3}$ Ex- Medical Superintendent, Group of TB Hospitals, Mumbai \\ ${ }^{4}$ National Chair, Clinical Pharmacology, ICMR
}

\begin{abstract}
Background: Tuberculosis is a global health problem and emergence of MDR TB is a major threat to tuberculosis care and control. Treatment of MDR TB is challenging due to toxicity of second-line drugs used. Elderly population has several risk factors that can increase their susceptibility to ADR.

Methods: A retrospective analysis of records of MDR TB patients admitted, to Group of T.B. Hospital, a specialized TB hospital in Mumbai, India, during January 2016 - December 2016, was carried out to evaluate ADRs in patients $\geq 60$ years of age and compare it with patients $<60$ years. ADRs were assessed for system organ classification, seriousness, severity causality, related suspected drugs, preventability using standard methods, and for possible risk factors.

Results: Out of 732 patients admitted, 33 were $\geq 60$ years, 99 (three times) patients $<60$ years were randomly identified from the remaining 699 of which 91 with required records were included in the analysis. Patients $\geq 60$ years had significantly greater incidence of ADRs compared to $<60$ years age group. ADRs like vomiting, giddiness, otovestibular toxicity (tinnitus and vertigo) and hearing loss were significantly more in patient $\geq 60$ years. Patients $\geq 60$ years and with diabetes mellitus had significantly more ADRs as compared to patients < 60 years and with DM. ADRs were found to be possibly preventable by proper preventive measures and management as per guidelines.

Conclusion: Elderly population is increasing worldwide and is vulnerable to more ADRs due to comorbidities, pharmacokinetic, pharmacodynamics changes and social factors. Recognition of this vulnerability, emphasis on careful history, counselling and monitoring will help prevent ADRs and better manage elderly DR TB patients.
\end{abstract}

\section{Introduction}

Tuberculosis is a global public health problem, and is one of the top ten causes of death worldwide and has caused more deaths than HIV in $2015^{1}$. India has the largest number of TB patients with an estimated incidence of 2.8 million cases of TB out of a global incidence of 10.4 million. Despite extensive tuberculosis control efforts on the part of World Health Organization (WHO) and local health departments, the tuberculosis epidemic continues to ravage the developing world, affecting all susceptible individuals, including the aging adults ${ }^{2}$. 
The emergence of multi drug resistant tuberculosis (MDR TB) is a major threat to global tuberculosis care and control. MDR TB is defined as resistance to isoniazid and rifampicin with or without resistance to other anti $\mathrm{TB}$ drugs. It takes longer to treat MDR TB and itis associated with higher mortality ${ }^{3}$. Treatment of MDR TB is challenging due to toxicity to second line drugs ${ }^{4}$.

Adverse drug reactions are a major cause of hospital admissions mortality, morbidity and increased health care costs in the treatment of MDR TB. Studies have shown that the risk factors associated with adverse reactions to antituberculosis drugs are: gender, race/ethnicity, nationality, age, weight, marital status, treatment regimen, genetic factors, anemia, co-infection with HIV, HBV, or HCV, diabetes, liver disease, hypoalbuminemia, hyponatremia, lymphopenia, and alcohol, tobacco, or illicit drug use ${ }^{5}$.. Age is a very important factor which affects the occurrence of ADRs ${ }^{6}$.Population over 60 is increasing rapidly and related health care issues have been focus of attention. The International Conference on Harmonization considers older people a 'special population', as they differ from younger adults in terms of comorbidity, polypharmacy, pharmacokinetics and greater vulnerability to adverse drug reactions ${ }^{7}$.

Although, ADRs to first line to antitubercular drugs in elderly patients have been reported, there are only a few reports on ADRs to MDR TB drugs in elderly. While reporting and analysis of ADRs is important, assessing preventability and guidelines for preventing ADRs is crucial.

The present study was carried out to evaluate ADRsdue to antitubercular drug in MDRTB patients $\geq 60$ years of age, focusing on risk factors and preventability.

\section{Methods}

This is a retrospective study of records of MDRTB patients admitted to GTB hospital during January 2016- Dec 2016 Period. GTB hospital is a 1200 bedded specialized TB hospital located in Mumbai in India, 200 beds are reserved for drug resistant patients. Patients are admitted for disease related complication or any adverse drug reaction. Indoor records of patients admitted during 1stJanuary 2016 to $31^{\text {st }}$ December 2016 period were screened for patients of more than or equal to 60 years of age. Thirty three patients were found to be $\geq 60$ years of age. Out of remaining 699 patients $<60$ years of age, 99 patients i.e. three times the number of older patients, were randomly selected for the comparative group. Complete information was available for 91 of these 99 patients and their records were used for the comparative analysis. Patients who were not admitted during $1^{\text {st }}$ January to $31^{\text {st }}$ December 2016 period were excluded. Patient information ondemography, signs and symptoms, treatment regimen and investigations was extracted from the hospital records of the hospital admitted patients. W.H.O defines adverse drug reaction (ADR) as "Any response to a drug which is noxious, unintended and occurs at doses used in man for prophylaxis, diagnosis or therapy."

ADRs were identified from the case history, clinical examination and investigations and were considered serious if recorded as cause for admission. ADRs were classified according to the system organ classification of the WHO.

ADRs were assessed for causality using WHO criteria as certain, probable, possible, unlikely, unclassifiable and for preventability using Schumoch and Thornton criteria as definitely preventable, possibility preventable, not preventable, unevaluable

The data was entered in the MS Excel sheet and statistical analysis was carried out using SPSS software version 16. Descriptive statistics (mean and standard deviation) were done for quantitative parameters and various parameters were compared using chi square method.

Permission to access patient data was obtained from the Medical Superintendent of TB Hospital. Ethics committee permission was not deemed necessary as it was retrospective analysis of patient records and part of routine activity of the hospital. 


\section{Results}

The screening of records of patients admitted during $1^{\text {st }}$ from January 2016 to $31^{\text {st }}$ December 2016 period showed that 732 patients were admitted to DRTB ward. Data of 33 patients $\geq 60$ years and 91 patients of $<60$ years of age (whose records were complete) were extracted, compiled and analyzed.

The mean age of patients in the age group $<60$ years was found to be 30.84+- 12.06 years and in the age group $\geq 60$ years it was $63.60+/-3.28$ years.

This hospital does not have facilities for managing extra pulmonary TB. Thus most cases (122) were with pulmonary TB, only two had extra- pulmonary TB. All cases were of Drug resistant TB however whether it was primary or secondary resistance could not be evaluated as that data was not entered in the records for most (except 5 cases). 104 cases were receiving conventional MDR TB regimen, 78 were on intensive phase (69 months) and 26 were in continuation phase, (18 months). Twenty patients were on treatment regimen for XDR patients, of which 16 were in intensive phase (6-12 months) and four were in continuation phase (18 months)

The analysis showed that the ADRs were present in $63.63 \%$ of older age group, as compared to $29.67 \%$ of younger age group ( $\mathrm{P}$ value of $<0.05$ ).

Table 1 Patient information

\begin{tabular}{|l|c|c|c|}
\hline Parameter & $<\mathbf{6 0 y e a r s}$ & $\geq \mathbf{6 0}$ years & P value \\
\hline Total no. of participants & 91 & 33 & \\
\cline { 1 - 3 } Male & $55(60.44 \%)$ & $28(84.85 \%)$ & $<0.02$ \\
\cline { 1 - 3 } Female & $36(39.56 \%)$ & $05(15.15 \%)$ & \\
\hline DM & $11(12 \%)$ & $21(64 \%)$ & $<0.05$ \\
\hline ADRs & $27(29.67 \%)$ & $21(63.63 \%)$ & $<0.05$ \\
\hline DM \& ADR & 00 & $14(66.7 \%)$ & $<0.001$ \\
\hline MDR & $74(81.31 \%)$ & $30(90.90 \%)$ & NS \\
\hline XDR & $17(18.68 \%)$ & $03(9.09 \%)$ & NS \\
\hline BMI (10-18.4) & $54(79 \%)$ & $13(39 \%)$ & NS \\
\hline
\end{tabular}

$\mathrm{DM}=$ Diabetes, $\mathrm{ADRs}=$ Adverse Drug Reactions, MDR= Multi - Drug Resistance, $\mathrm{XDR}=$ Extreme Drug Resistance, $\mathrm{BMI}=$ Body Mass Index, NS- Not significant

The most frequent system-organ classes affected by ADRs were gastrointestinal system, central nervous system and otovestibular system and ear disorder (12\%) (Table 2). The most common adverse drug reaction in both the age groups was vomiting. Other adverse drug reactions observed were giddiness, hepatic dysfunction, blurred vision, skin rashes, hypothyroidism, renal failure, suicidal tendency and abnormal behavior. Vomiting, giddiness, hearing loss, tinnitus, and vertigo were significantly more in the $\geq 60$ year age group (Table 2). All cases were considered serious (WHO criteria of hospital admission for serious ADRs and severe and all were considered as possibly preventable. It was difficult to do causality assessment due to inadequate information in case records.

Some of the risk factors for ADRs such as malnutrition, concomitant diseases were present in high proportion. A high proportion (64\%) of patients in the age group $\geq 60$ years was suffering from diabetes as against (12\%) of patients in $<60$ year group $(\mathrm{P}<0.05)$. Sixty seven percent of the patients suffering from diabetes in the age group $\geq$ 


\section{JMSCR Vol||06||Issue||03||Page 1038-1045||March}

60 year had reported at least one ADR compared to $0 \%$ in patients with DM in the $<60$ year age group (Table 1). $(\mathrm{p}<0.001)$ It was seen that $54.03 \%$ of the patients were under weight as per body mass index ratio. $79 \%$ of $<60$ year and $39 \%$ of $\geq 60$ year (N.S) were malnourished. ADRs in malnourished patients were $40.2 \%$ compared to
$3.5 \%$ in normal - high BMI cases. Fifteen percent of the patients in older age group were suffering from hypertension. Two patients in the older age group were found to be alcohol users and one patient a tobacco user. Two of the patients in the age group $<60$ years were HIV positive.

Table 2: Types of ADRs, casually related drugs and preventability

\begin{tabular}{|c|c|c|c|c|c|c|}
\hline $\begin{array}{ll}\text { Adverse } & \text { Drug } \\
\text { Reaction } & \end{array}$ & $\begin{array}{l}\text { Organ system } \\
\text { classification }\end{array}$ & $\begin{array}{c}\text { Total } \\
<60 y r s \\
\text { n=91 }\end{array}$ & $\begin{array}{c}\text { Total } \\
\geq 60 y r s \\
n=33\end{array}$ & $\begin{array}{c}\mathbf{P} \\
\text { value } \\
< \\
\end{array}$ & $\begin{array}{c}\text { Causality } \\
\text { Related } \\
\text { drugs }\end{array}$ & Preventability \\
\hline Giddiness & $\begin{array}{c}\text { Central Nervous } \\
\text { System }\end{array}$ & $1(1.09 \%)$ & $\begin{array}{c}6 \\
(18.18 \%)\end{array}$ & 0.001 & $\begin{array}{l}\text { Km, Eto, } \\
\text { Lfx, Z }\end{array}$ & $\begin{array}{c}\text { Possibly } \\
\text { preventable }\end{array}$ \\
\hline Vomiting & $\begin{array}{c}\text { Gastrointestinal } \\
\text { disorders }\end{array}$ & $12(13.08 \%)$ & $7(21.2 \%)$ & 0.05 & Eto, Z, E & $\begin{array}{c}\text { Possibly } \\
\text { preventable }\end{array}$ \\
\hline $\begin{array}{l}\text { Hepatic } \\
\text { dysfunction }\end{array}$ & $\begin{array}{c}\text { Hepatobiliary } \\
\text { disorders }\end{array}$ & 2 & 1 & NS & Z, Eto, Pas & $\begin{array}{c}\text { Possibly } \\
\text { preventable }\end{array}$ \\
\hline $\begin{array}{l}\text { Abnormal } \\
\text { Behavior }\end{array}$ & $\begin{array}{l}\text { Central Nervous } \\
\text { System }\end{array}$ & 3 & 0 & NS & Cs & $\begin{array}{c}\text { Possibly } \\
\text { preventable }\end{array}$ \\
\hline $\begin{array}{l}\text { Suicidal } \\
\text { Tendency }\end{array}$ & $\begin{array}{c}\text { Central Nervous } \\
\text { System }\end{array}$ & 1 & 0 & NS & $\mathrm{Cs}$ & $\begin{array}{c}\text { Possibly } \\
\text { preventable }\end{array}$ \\
\hline Irreverent Talk & $\begin{array}{l}\text { Central Nervous } \\
\text { System }\end{array}$ & 1 & 0 & NS & Cs & $\begin{array}{c}\text { Possibly } \\
\text { preventable }\end{array}$ \\
\hline Hearing Loss & Ear disorders & 0 & $\begin{array}{c}4 \\
(12.12 \%)\end{array}$ & 0.001 & $\mathrm{Km}, \mathrm{Cm}$ & $\begin{array}{c}\text { Possibly } \\
\text { preventable }\end{array}$ \\
\hline $\begin{array}{ll}\text { Tinnitus } & \text { and } \\
\text { vertigo } & \end{array}$ & Oto Vestibular & 0 & $\begin{array}{c}4 \\
(12.12 \%)\end{array}$ & 0.001 & $\mathrm{Km}, \mathrm{Cm}$ & $\begin{array}{c}\text { Possibly } \\
\text { preventable }\end{array}$ \\
\hline Blurred Vision & Eye Disorder & 0 & 1 & NS & E, Lnz & $\begin{array}{c}\text { Possibly } \\
\text { preventable }\end{array}$ \\
\hline Skin Rashes & $\begin{array}{l}\text { Dermatological } \\
\text { disorder }\end{array}$ & 1 & 0 & NS & All AKT & $\begin{array}{c}\text { Possibly } \\
\text { preventable }\end{array}$ \\
\hline Hypothyroid & $\begin{array}{c}\text { Endocrinology } \\
\text { disorder }\end{array}$ & 1 & 0 & NS & Eto, Pas & $\begin{array}{c}\text { Possibly } \\
\text { preventable }\end{array}$ \\
\hline Renal Failure & $\begin{array}{l}\text { Excretory system } \\
\text { disorder (kidney) }\end{array}$ & 1 & 0 & NS & $\mathrm{Km}, \mathrm{Cm}$ & $\begin{array}{c}\text { Possibly } \\
\text { preventable }\end{array}$ \\
\hline
\end{tabular}

\section{Discussion}

Among 33 patients in the age group $\geq 60$ years, 21 (63.63\%) patients had at least one adverse reaction, compared to $29.67 \%$ patients from less than 60 year age group. This indicates the need for greater evaluation of susceptibility of older patients for developing MDR TB antitubercular drug induced ADRs. A number of studies have shown that elderly patients are more likely to have ADRs.

Farazi reported in a study in Iran, age $>50$ years, confection with HIV, smoking, retreatment and comorbidities to be risk factors for major ADRs with $1^{\text {st }}$ line antitubercular drugs ${ }^{8}$. In a study in India, Asati ${ }^{9}$ reported that ADRs were more frequent in females and in elderly patients receiving $1^{\text {st }}$ line drugs. Dophne ${ }^{10}$ also reported more side effects in patients over 60 year with $1^{\text {st }}$ line drugs

In a study in Addis Abbaba $^{11}$, in 73 MDR TB patients aged $18-65$ year admitted to TB hospital and treated with $2^{\text {nd }}$ line drugs, anorexia $(83.3 \%)$ nausea vomiting $(82 \%)$ gastritis $(64 \%)$ diarrhea (97\%) hearing loss (83\%) arthralgia (46.6\%) dermatological (37.5\%) blurry vision (19.4\%) dizziness (13.9\%) psychosis (14\%) depression (22.2\%) were some of the ADRs observed. In age group $40-65$ years dehydration was more frequent than in younger patients. 
Issues related to elderly population have been recently reviewed and are of concern ${ }^{12}$. Gerontologists define elderly as young old (65$74)$, middle old (75-84) and very old (>85). The cut off age for elderly in India is 60 years. The population over 60 is rapidly increasing in the world's most populist countries. In India, 5\% of the population wasover 60 in 1950 and $7.3 \%$ in 2000; the proportion is projected to be $19 \%$ in 2050; in China, comparative figures are $7.7 \%$, $10 \%$ and $32 \%$. The number of elderly people in India is projected to reach 158.7 million in 2025 and by 2050 , to surpass the population of children below the age of 14 years. Globally the elderly population (aged $>=60$ years) is expected to increase to more than 2 billion in 2050 .

The prevalence of non-communicable diseases and the morbidity due to re-emerging infectious diseases is high in older people, and varies across gender, area of residence, and socioeconomic status. According to National Sample Survey Office India data, $28.3 \%$ of older people in rural and $36.8 \%$ in urban areas, suffer from one or more diseases.

About 106 out of every 1000 suffer from heart diseases and 55 of 1000 in urban area have some sort of disability such as poor vision, hearing difficulty or locomotive impairment. According to the non-governmental organization help age 2014 report, more than a quarter of existing 100 million Indian older people are under weight and nearly $1 / 3$ has undiagnosed hypertension. Furthermore, about 1 old individual in 5 is depressed.

$2 / 3$ of the elderly population lives in villages, half are of poor socio-economic status and of this, 70\% are women, all of which further jeopardizes their health status and access to care.

Although person aged over 65 years represent about $13 \%$ of the population, they consume $1 / 3$ of all medicines. Over prescribing is a serious concern. Older patients often consult several doctors who may be unaware of prior consultations, add more drugs, and thereby complicate matter further. On the other hand, under prescribing of appropriate medications is also of concern. Studies of drug effectiveness often exclude the older population whereby the benefit risk ratio is not known.

The pharmacokinetic and pharmacodynamic properties of drugs change as adults grow older, for e.g. older patients have an increased volume of distribution for lipid soluble drugs as the proportion of fat to lean body mass increases with age. Renal function declines, increasing concentration of renally excreted drugs like aminoglycosides. Sensitivity to centrally acting drugs like benzodiazepines increases.

Formulations packaging and package inserts are unmindful of the needs of older people, the elderly may have mechanical difficulties making it hard to break tablets by hand or open medicine packs, visual difficulties making it hard to read packages labeling, and swallowing problems that necessitates liquid preparations. All these factors limit access to beneficial drug therapy, reduce compliance, and increase adverse drug reactions.

Several European and International recommendations have been made regarding the development, formulation, and drug product design for the elderly. The ICH Q8 guideline "Pharmaceutical development". European Medicines Agency (EMA) good practice guide on risk minimization and prevention of medication errors, and EMA committee on Human medicinal product. QWP (Quality Working Party) reflection paper, all consider aspects of medicines for older people. Indian drug regulations requires prescribing information ( in packaging insert) on the use of drugs in special population including geriatrics. But there is no provision to design package or label specifically keeping in mind the needs of the elderly.

Schedule Y of Drugs And Cosmetics Act (DCA) of India stipulates that older subject should be included in meaningful numbers in phase 2 and phase 3 trials at the sponsor's option., if the diseases affect elderly people. There is no specific requirement in Indian Law that requires reporting of clinical trials result to be disaggregated by age. 
Results of our study show significantly higher ADRs in elderly compared in $<60$ years age group. Patients with diabetes had significantly higher ADRs. Patients $\geq 60$ age had significantly more vomiting, giddiness, hearing loss, tinnitus and vertigo.

ADRs were assessed as possibly preventable with proper selection of drug dose, emphasis on proper history, early diagnosis and proper management. Elderly patients may have existing dizziness, low hearing, and depression.

ICMR and Central TB Control division have developed manual and Ready Reckoner for general practitioners for prevention and management of ADRs to antitubercular drugs. Ready Reckoner provides in a tabular format details of ADRs, suspect drugs, differential diagnosis, prevention and management ${ }^{13}$.

ADRs can be prevented for e.g. by taking anti TB drugs with food to prevent vomiting. For psychosis, careful monitoring and psychiatric counseling at the start of treatment in patients at risk, for Oto toxicity and hearing loss, monitoring of early symptom, can prevent worsening and permanent ear damage. Regular ophthalmologic examination can be done to prevent blurring of vision or blindness.

There is need to recognize that elderly population is increasing, will form a proportion of TB cases and will need special attention due to their vulnerability.

\section{Conclusion}

MDR TB drugs could cause significantly more adverse drugs reaction in the elderly due to various age related risk factors such as concomitant diseases, altered pharmacokinetic and pharmacodynamics and use of multiple drugs. The results of our study suggest that the protocol of anti-TB therapy and management of ADRs in older patients needs to be specially emphasized and may need some revision to prevent known ADRs.

\section{Limitation}

The current study was retrospective analysis of patient records and information regarding ADRs, concomitant diseases and other risk factors may be incomplete.

\section{Acknowledgement}

We are thankful to the medical record officer, TB Hospital for providing all necessary documents for the study.

\section{References}

1. World Health Organisation. Global TB report 2016. WHO/HTM/TB/2016.13

2. T. Yoshikawa Thomas and Shobita Rajagopalan. Tuberculosis and Aging: A Global Health Problem. Clinical Infectious Diseases, Volume 33, Issue 7, 1 October 2001, Pages 1034-1039. https://doi.org/10.1086/322671.

3. Atal Sood, Rekha Bansal, Aradhna Sharma. Profile of adverse drug reactions in patients on anti-tubercular drugs in a sub Himalayan tertiary care teaching hospital. International Journal of Research in Medicinal Sciences. 2016; 4(10):44654471.

4. Kapadia VK, Tripathi SB. Analysis of 63 patients of MDR TB on DOTS plus regimen: An LG hospital, TB unit, Ahmedabad experience. Guj Med J. 2013; 68(2):52-7.

5. Laíse Soares Oliveira Resende, Edson Theodoro dos Santos-Neto. Risk factors associated with adverse reactions to antituberculosis drugs. J Bras Pneumol. 2015; 41(1):77-89.

6. Alomar MJ. Factors affecting the development of adverse drug reactions (Review article). Saudi Pharmaceutical Journal: SPJ. 2014; 22(2):83-94. doi:10.1016/j.jsps.2013.02.003.

7. Davies EA, O'Mahony MS. Adverse drug reactions in special populations - the elderly. British Journal of Clinical 
Pharmacology. 2015; 80(4):796-807. doi:10.1111/bcp.12596.

8. Farazi A. Sofian M, Jabbariasi M, Keshavarz S, Adverse reactions to antituberculosis drugs in Iranian Tuberculosis patients. Tuberculosis research and treatment. 2014, article ID 412893.

9. Asati A, Indurkar M, Profile of adverse drug reactions in TB patients taking ATT Journal of Medical Science and Clinical Research 2016, 12, 14589 - 14592

10. Daphne Y, Marthe etal. Incidence of serious side effects from first line antituberculosis drugs among patients treated for active tuberculosis. Am. J. Resp. care Med, 2003,167, 1472-1477
11. Bezu H, Seifu D, Yimer G, Mebrhatu T, Prevalence and risk factors of adverse drug reactions, associated with multidrug resistant tuberculosis treatment in selected treatment centers in Addis Ababa Ethiopia. Journal of Tuberculosis Research 2014, 2, 144-154

12. Kshirsagar NA and others, Safer prescriptions for the elderly challenges and solutions from India. The Lancet global heath, $20 \mathrm{Jul}$ 2017, blog. 16669358474- b7 afe 8 ba 47 _ 0 .jgp.

13. ICMR and central TB division India :Prevention and management of ADRs to antitubercular drugs . Ready reckoner for medical officers, 2016, https://tbcindia.gov.in.

\section{Appendix}

Hajar in his study showed that older people are more than twice as susceptible to ADRs as younger people. The various factors that make older people more susceptible are polypharmacy and physiological changes affecting the pharmacokinetics and pharmacodynamics of many drugs or poor compliance due to cognitive impairment or depression. As people age, the amount of water in the body decreases and the amount of fat tissue relative to water, increases, the kidneys are less able to excrete drugs into the urine, and the liver is less able to metabolize many drugs. Jimmy and Padma in their study concluded that the incidence of ADRs among elderly adults and older adults was significantly higher than other age groups. Because of all agerelated changes, the drugs tend to stay in an older person's body much longer than they would in a younger person's body, prolonging the drug's effect and increasing the risk of side effects (Klotz, 2009). Another important factor is the increase in multi-morbidity in older people which leads to increased prescribing in this population and thus polypharmacy increases the risk of drug interactions and adverse events. The changes in organ mass and blood circulation along with changes in body composition with age increases the probability of ADRs in older population. A reduction in liver size of $25-35 \%$ and a decrease in hepatic blood flow of more than $40 \%$ are seen in healthy ageing, resulting in reduced drug clearance. The glomerular filtration rate (GFR) is significantly affected by disease states common in the elderly e.g. hypertension and heart failure. Ageing is associated with physiological changes that affect how medicines are handled, including alterations in volumes of drug distribution, metabolism and clearance which can prolong half-life, increase potential for drug toxicity and the likelihood of adverse drug reactions ${ }^{7}$.

The commonest adverse drug reactions in MDR patients are CNS (27.5\%), gastrointestinal tract (GIT) (19\%), psychiatric $(12.5 \%)$, otovestibular $(8 \%)$ and ophthalmic $(0.6 \%)^{3}$. One of the studies showed that psychiatric ADRs such as depression and psychosis constituted $12.5 \%$ in elderly population ${ }^{3}$. The drug which is known to cause psychosis as a late manifestation is cycloserine and is also a part of the MDR treatment regimen ${ }^{9}$. All aminoglycosides given in MDR TB treatment are known to be otovestibulo- toxic ${ }^{10}$. There is a scarcity of published literature of DR-TB among elderly patients from India ${ }^{12}$. One of the studies showed that a significant percentage (40\%) of elderly patients had chronic diseases and were on a long term medication: the most common co-morbid illness being diabetes mellitus $(16 \%)^{13}$. These co morbid diseases in elderly population make them vulnerable and increase the chance of having an ADR. Multiple diseases make patients more vulnerable to ADRs due to the presence of many diseases and the use of many drugs. If MDR TB is accompanied with other diseases, these diseases might have an impact on the response of the body to anti TB drugs since the metabolic processes of the body will be affected negatively. In patients with 
renal failure, the effect of drugs on the kidneys is lessened because of the loss of the site of action for these drugs. This leads to increasing the dose which in turn leads to more ADRs ${ }^{20}$.

One of the common ADRs in MDR TB treatment is hepatotoxicity. One of the studies showed that being less than 65 years of age is a protective factor for hepatitis, whereas another showed that being $\leq 60$ years of age is a protective factor for drug-induced hepatotoxicity. Other common ADRs include arthralgia, exanthema, and unspecified reactions (kidney disorders, jaundice, hearing loss, liver problems, and skin rash). Another study showed that age $(<60$ years) was a significant protective factor for unspecified reactions. According to two studies, elderly patients (over 60 or 65 years of age) are more likely to have ADRs due to the fact that elderly individuals have a slower metabolism, which is due to reduced enzymatic activity, reduced hepatic clearance, and reduced availability of essential endogenous cofactors 5 .

The present study aimed at assessing ADRs and co-morbid conditions among elderly population suffering from MDR tuberculosis in an attempt to improve identification of ADRs in elderly patients and formulate prevention strategies targeting the prescribing and monitoring stages of pharmaceutical care because drugs are less likely to be studied extensively in extremes of age, and drug absorption and metabolism are more variable and less predictable in this age group. Efforts are needed to predict and prevent the occurrence of ADRs in older population. The study also aimed at comparing these parameters with non-elderly population. Also, male preponderance was observed in the present study (males 58.87\% and females 33.06\%), other studies $^{4,10}$ from India have shown similar findings. Dheeraj Gupta's study from Northern India showed male preponderance of $66 \%$ while Kapadia VK's study from Ahmedabad reported $63.49 \%$ males and $36.51 \%$ female patients with ADRs.

Malnourishment was seen in $54 \%$ of the patients having ADRs in the present study. Flora S Nyakistudy ${ }^{11}$ from Tanzania reported 53\% MDR patients suffering from malnourishment, similarly a study by Sachin Atre $^{12}$ from Mumbai, India reported a high percentage $(75 \%)$ of malnourishment among MDR TB patients. These findings are in consistent with the findings of our study where a high proportion of patients were found to be malnourished. Malnourishment is a major risk factor for ADRs and thus, should be taken into account while managing TB patients. Of the total patients, $67 \%$ of the patients were suffering from diabetes and had at least ADR. One of the studies showed similar findings where diabetes mellitus was seen in $25.8 \%$ patients and $70 \%$ of those patients had with diabetes ${ }^{12}$. Another study ${ }^{13}$ from central India showed that the incidence of ADR was more in patients with diabetes (80\%) than those without diabetes (47\%). Therefore, patients with concomitant diseases are more likely to have ADRs and should be treated and managed appropriately. The ADRs ranged from $57.14 \%$ to $69.2 \%$ in MDR TB patients in a number of studies ${ }^{4,13,14}$, and 15 which is consistent with the findings of our study. It is known that not all patients develop the same level and type of ADRs. Age is a very important factor which affects the occurrence of ADRs. Elderly patients with multiple medical problems who are taking multiple drugs, those who have a history of ADRs, and those with a reduced capacity to eliminate drugs are at high risk for ADRs. Practice guidelines are often drawn from the results of clinical trials from which frail, older and comorbid people have been excluded. The extrapolation of evidence from younger, healthier and physiologically different populations to older people make it difficult to predict reliably the prevalence and nature of adverse drug events that can be expected in 'real world' usage. The main contributors to altered pharmacokinetics are age related changes in organ mass and blood circulation along with changes in body composition. Thus, it can be concluded that ADRs observed more among elderly TB patients make it important to consider concomitant diseases, age, and other risk factors while treating and managing TB especially MDR TB patients. Some easily manageable ADRs like vomiting associated with MDR treatment can be minimized by administering antiemetics as well as consuming tablets along with food. All MDR patients should undergo screening for immuno-compromised state and if diagnosed, strict management of the same is essential. 